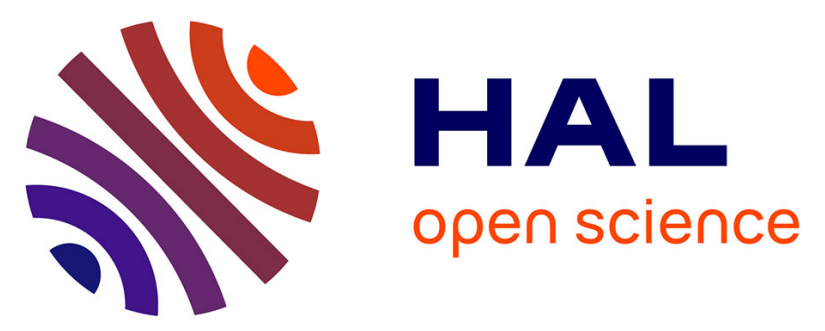

\title{
Relevance and feasibility of a systematic screening of multimorbidities in patients with chronic inflammatory rheumatic diseases
}

Claire Daien, Amandine Tubery, Mégane Beurai-Weber, Guilhem Du Cailar, Marie-Christine Picot, Audrey Jaussent, François Roubille, Jean-David

Cohen, Jacques Morel, Jean Bousquet, et al.

\section{To cite this version:}

Claire Daien, Amandine Tubery, Mégane Beurai-Weber, Guilhem Du Cailar, Marie-Christine Picot, et al.. Relevance and feasibility of a systematic screening of multimorbidities in patients with chronic inflammatory rheumatic diseases. Joint Bone Spine, 2018, 86 (1), pp.49-54. 10.1016/j.jbspin.2018.03.016 . hal-01790556v2

\section{HAL Id: hal-01790556 \\ https://hal.umontpellier.fr/hal-01790556v2}

Submitted on 23 Apr 2020

HAL is a multi-disciplinary open access archive for the deposit and dissemination of scientific research documents, whether they are published or not. The documents may come from teaching and research institutions in France or abroad, or from public or private research centers.
L'archive ouverte pluridisciplinaire HAL, est destinée au dépôt et à la diffusion de documents scientifiques de niveau recherche, publiés ou non, émanant des établissements d'enseignement et de recherche français ou étrangers, des laboratoires publics ou privés. 


\title{
Relevance and feasibility of a systematic screening of multimorbidities in patients with chronic inflammatory rheumatic diseases
}

\author{
Claire I. Daïen ${ }^{\mathrm{a}, \mathrm{b}, \mathrm{c}, *}$, Amandine Tubery ${ }^{\mathrm{a}, \mathrm{b}}$, Mégane Beurai-Weber ${ }^{\mathrm{a}, \mathrm{b}}$, Guilhem du Cailar ${ }^{\mathrm{b}, \mathrm{d}}$, \\ Marie-Christine Picot ${ }^{\mathrm{e}}$, Audrey Jaussent ${ }^{\mathrm{e}}$, François Roubille ${ }^{\mathrm{b}, \mathrm{f}}$, Jean-David Cohen ${ }^{\mathrm{a}, \mathrm{b}}$, \\ Jacques Morel ${ }^{\mathrm{a}, \mathrm{b}, \mathrm{c}}$, Jean Bousquet ${ }^{g}$, Pierre Fesler ${ }^{\mathrm{b}, \mathrm{d}, \mathrm{e}, \mathrm{h}}$, Bernard Combe $^{\mathrm{a}, \mathrm{b}}$ \\ a Department of Rheumatology, CHU de Montpellier, 34000 Montpellier, France \\ ${ }^{\mathrm{b}}$ Montpellier University, 34000 Montpellier, France \\ c Institut de génétique moléculaire Montpellier, UMR5535, CNRS, 34000 Montpellier, France \\ ${ }^{\mathrm{d}}$ Internal medicine and hypertension, CHU Montpellier, 34000 Montpellier, France \\ e Department of medical information, Montpellier University, 34295 Montpellier, France \\ ${ }^{\mathrm{f}}$ Department of cardiology, CHU de Montpellier, 34295 Montpellier, France \\ g MACVIA-France, 34000 Montpellier, France \\ ${ }^{\mathrm{h}}$ National Institute for Health and Medical Research (INSERM), U1046, 34000 Montpellier, France
}

Objectives: EULAR recently proposed to screen multimorbidities in chronic inflammatory rheumatic diseases. The aims of the study were to define the most common multimorbidities in chronic inflammatory rheumatic diseases, compare the screening approach performed in the clinic with the recent EULAR recommendations, validate the points to consider for the systematic standardized multimorbidity screening proposed by EULAR and assess feasibility of such a screening in a daily clinic.

Methods: Data were collected prospectively during a 1-day multimorbidity clinic. Diabetes, hypertension, CVD damage, chronic respiratory diseases, osteoporosis and preventive measures were assessed. The comparison with EULAR points to consider was performed retrospectively.

Results: We included 200 consecutive patients (157 with rheumatoid arthritis, 37 spondyloarthritis, and 6 connective tissue diseases or vasculitis). The most common multimorbidities already diagnosed in our patients were hypertension (26\%) and diabetes (7.5\%). Screening showed that $61.5 \%$ (CI95\%: $54.6 \%$ $67.9 \%$ ) patients presented at least one undiagnosed or uncontrolled diseases: diabetes (6\%), hypertension (20.6\%), dyslipidemia (16.1\%) valvulopathies (16.8\%), peripheral artery disease $(4.5 \%)$; carotid stenosis (6.5\%) and aortic aneurysm (5.5\%). Overall, 39.9\% patients had incomplete cancer screening and 52.8\% incomplete vaccine schedule. Undiagnosed pulmonary obstruction and risk of sleep apnea were suspected in $15.5 \%$ and $40.1 \%$ patients, respectively.

Conclusion: This study underlines the relevance of a systematic screening of multimorbidities in chronic inflammatory rheumatic diseases and its feasibility in a 1-day clinic. Spirometry and sleep apnea screening should be added to EULAR points to consider. The long-term impact of such screening needs to be evaluated.

\section{Introduction}

Major chronic diseases include the four major noncommunicable diseases (NCDs) listed by the World Health

* Corresponding author. Rheumatology Department, Hôpital Lapeyronie, 371 Avenue du Doyen Gaston Giraud, 34295 Montpellier Cedex 5, France.

E-mail address: cidaien@gmail.com (C.I. Daïen).
Organization (WHO)-cardiovascular diseases, cancers, chronic respiratory diseases and diabetes-as well as other NCDs such as mental disorders and skeletomuscular diseases [1]. These diseases represent the predominant health problem of the century. The trend for managing chronic diseases is evolving toward integrative and holistic approaches. Chronic diseases tend to cluster; patients present concomitant or consecutive diseases that are intertwined with aging. The term multimorbidity is more appropriate than comorbidity in inflammatory rheumatic diseases as the primary disease is unknown. To tackle chronic diseases in their totality 
so as to reduce their burden and societal impact, NCDs should be managed together with their multimorbidies [2].

Patients with chronic inflammatory rheumatism including rheumatoid arthritis (RA), axial spondyloarthritis (axSpA), psoriatic arthritis (PsA), connective tissue disease and vasculitis are at high risk of cardiovascular disease (CVD), infections and osteoporosis because of the disease itself or its treatment. Chronic respiratory diseases are not considered major multimorbidities, although some studies have found an increased prevalence of chronic obstructive pulmonary disease (COPD) or obstructive sleep apnea syndrome (OSAS) in patients with RA $[3,4]$.

The European League Against Rheumatism (EULAR) recently proposed a standardized protocol for reporting occurrence of the comorbidity and current treatments; screening for disease or for risk factors and prevention in patients with chronic inflammatory rheumatic diseases [5]. The selected multimorbidities are cardiovascular diseases, malignancies, infections, gastrointestinal diseases, osteoporosis, and depression. Lung diseases and sleep apnea were not considered.

After WHO recommendations to study the four major chronic diseases together, the multimorbidity clinic of CHRU Montpellier, a reference site of the European Innovation Partnership on Active and Healthy Ageing, DG Santé and DG Cnect (MACVIA-LR) [2], was established to address chronic disease multimorbidities and aging. This initiative started in 2012 and concerned various chronic diseases such as diabetes, CVD, chronic respiratory diseases, mental health and rheumatic diseases. Patients with one of these chronic diseases underwent standardized screening of multimorbidities. In a pilot study, an extensive assessment was initially performed to select an optimal number of criteria. As part of this pilot study, 200 patients with chronic inflammatory rheumatism were investigated.

The aims of the study were to: define the most common multimorbidities in chronic inflammatory rheumatic diseases, compare the screening approach performed in the clinic with the recent EULAR recommendations, validate the points to consider for the systematic standardized multimorbidity screening proposed by EULAR and assess feasibility of such a screening in a daily clinic.

\section{Methods}

\subsection{Study design}

Multimorbidities were studied in consecutive patients with chronic inflammatory rheumatic diseases in a 1-day multimorbidity clinic by using a standardized protocol for the four chronic diseases listed by the WHO and their major consequences. Preventive measures such as vaccinations and cancer screening were also checked. The supplementary material S1 [Appendix A, Material $\mathrm{S} 1$; see the supplementary material associated with this article online]shows the estimated time needed for each parameter screened.

\subsection{Setting}

Out-patients with rheumatic diseases were recruited by rheumatologists at the rheumatology clinic of Montpellier University Hospital. This pilot study reports the systematic screening of the first 200 patients who were included from March 2014 to June 2015.

\subsection{Participants}

Treating rheumatologists referred patients to the clinical according to their will. This 1-day clinic could be proposed to every outpatient without any cardiologist follow-up and/or without any recent assessment of multimorbidity. The baseline characteristics of patients suggest that rheumatologists preferentially proposed the screening to patients at the highest CVD risk.

Diagnosis of RA, AS, PsA, connective tissue disease or vasculitis were made by experienced clinicians using classical criteria (i.e., American College of Rheumatology/EULAR 2010, Classification criteria for Psoriatic Arthritis [CASPAR] and Assessment of Spondyloarthritis international Society [ASAS] criteria).

The present study was approved by the medical ethics committee of Montpellier in accordance with the 1975 Declaration of Helsinki and with article R. 1121-3 of French public health law (April 26, 2006) (number CPPQ2016.11.01).

\subsection{Variables}

Questionnaires and explorations performed during the 1-day clinic were chosen from previous study [2]. Definitions and details are presented in supplementary material S2. The investigation included accurate collection of medical history and physical examination, blood analysis and imaging. All results were prospectively collected in computerized medical records.

The following items were assessed:

\section{- CVD:}

- weight and height with body mass index calculation, waist circumference,

- 4-limb blood pressure with systolic index calculation and 3 repeated measures, after 10 minutes of rest,

- electrocardiography,

- supra-aortic trunks and abdominal aorta ultrasonography, and echocardiography performed by experienced cardiologists. Carotid stenosis was defined by stenosis $>50 \%$; abdominal aorta aneurysm was defined as diameter $\geq 30 \mathrm{~mm}[6]$,

o fasting lipid measurement (total cholesterol, HDL, triglycerides, calulcated LDL),

- heart-SCORE ${ }^{\circledR}$ calculation: for RA patients, a modified HeartSCORE was used according to the EULAR 2015/2016 update without (mSCORE) or with the use of carotid ultrasonography (mUS-SCORE) [7].

- diabetes: fasting glycemia, HbA1c;

- chronic kidney disease: serum creatinin and MDRD calculation, albuminuria, urine test strip;

- osteoporosis: dual X-ray absorptiometry and FRAX calculation (performed only when osteoporosis risk factors including use of corticosteroids);

- chronic respiratory diseases: COPD was screened using first-level spirometry with forced expiratory vital capacity and forced expiratory volume in 1 second. COPD diagnosis requires a pulmonary function test before and after $\beta 2$-agonists [8]. However, due to the time constraints the reversibility was not assessed in the current study. OSAS was screened using Epworth, BERLIN questionnaires.

- Prevention: Cancer screening, vaccine schedule and regular dental follow-up (every year) were checked;

- Mental health: Depression and anxiety were assessed (Hospital Anxiety and Depression Scale [HADS], Quick Inventory of Depressive Symptomatology Self-report [QIDS-SR]).

\subsubsection{Osteoporosis}

Intake of anti-osteoporotic drugs was recorded. The decision to introduce a new anti-osteoporotic drug was based on dual $\mathrm{X}$ ray absorptiometry (DXA), Fracture Risk Assessment Tool (FRAX) calculation and French recommendations [9].

Well-being was assessed by the Medical Outcomes Survey Short Form 12 (SF-12). 


\subsubsection{Risk factors}

Risk factors of comorbidities such as obesity, tobacco, diet and alcohol were assessed by the CAGE instrument, physical exercise by the International Physical Activity Questionnaire 7 (IPAQ-7), and socioeconomic status by the EPICES (Evaluation de la Précarité et des Inégalités de santé dans les Centres d'Examens de Santé)(online supplement).

\subsubsection{Knowledge and adherence to treatment}

Knowledge and adherence to treatment were evaluated by the 4-item Morisky; therapeutic education was assessed by pharmacists and nurses [10].

\subsubsection{Inflammatory rheumatic diseases}

Inflammatory rheumatic diseases were assessed by a rheumatologist and a physiotherapist. Rheumatism abnormalities refer to therapeutic changes and/or physiotherapist advice.

\subsubsection{Medical synthesis of the day}

At the end of the day, the results of all the investigations were synthesized to the patients with a written document that was also addressed to the general practitioners. Referrals to cardiologist, lung disease specialist, and/or psychotherapist were proposed if necessary. Depending on the level of CVD risk and the multimorbidity, a control was planned at 1,2 or 5 years.

\subsection{Sample size}

Because this was a pilot study, the sample size was not estimated.

\subsection{Statistical methods}

Baseline data and abnormalities are described as follows: categorical variables are reported as number (\%), and quantitative variables are reported as mean \pm SD unless otherwise specified.
Prevalences of comorbidities are presented with their 95\% confidence interval. Missing data, when present, has not been imputed.

\subsection{Follow-up}

200 patients who performed a systematic screening in our clinic between January 2016 and December 2016 were contacted by phone between January 2017 and December 2017. They were asked if they had followed the recommendations given at the screening and if not, why.

\subsection{Role of the funding source}

MACVIA-LR. MACVIA-LR is a reference site of the European Innovation Partnership. The funding was not involved in the current study but served to organize meetings that initiated this work.

\section{Results}

\subsection{Participants}

Overall, 212 patients agreed to participate and 200 came to the clinic and underwent the multimorbidity evaluation. Except for DXA, which was not performed in 83 patients because it was not indicated, data for every investigation were available for more than $90 \%$ of patients. The flow of patients in the study is available as supplementary material S3.

Among the 200 included patients, 157 had RA, 25 had AS, 13 psoriatic arthritis, 3 vasculitis (2 ANCA vasculitis and 1 giant cell arteritis), 2 from systemic lupus erythematosus and one from polymyositis. The characteristics are summarized in Table 1.

\subsection{Impact of standardized multimorbidity screening for patients with chronic inflammatory rheumatic diseases}

The main results of the systematic screening are presented in Table 2. One-hundred twenty-three patients (61.5\%, CI95\%:

Table 1

Characteristics of patients with rheumatoid arthritis (RA) and spondyloarthritis (psoriatic arthritis and ankylosing spondylitis).

\begin{tabular}{|c|c|c|c|}
\hline & $\begin{array}{l}\text { All patients } \\
(n=200)\end{array}$ & $\mathrm{RA}(n=157)$ & Spondyloarthritis $(n=37)$ \\
\hline Age (years) & $59 \pm 11$ & $61 \pm 10$ & $49 \pm 12$ \\
\hline Female (\%) & 66.5 & 72.6 & 40.5 \\
\hline Body mass index $\left(\mathrm{kg} / \mathrm{m}^{2}\right)$ & $24.8(21.8-29.1)$ & $24.5(21.7-28.9)$ & $26.3(22.7-30.0)$ \\
\hline Obesity/overweight & $97(48.7)$ & $72(46.1)$ & $22(59.5)$ \\
\hline Disease duration (years) & $13(6-19)$ & $13(6-19)$ & $10(5-20)$ \\
\hline RF positivity (\%) & NA & 69.9 & NA \\
\hline Erosion (\%) & NA & 69.4 & NA \\
\hline DAS28-CRP & $2.3(1.6-3.2)$ & $2.4(1.7-3.3)$ & $1.5(1.3-2.5)(n=6)$ \\
\hline BASDAI & NA & NA & $3.9(2.5-4.5)(n=21)$ \\
\hline Ongoing steroids (\%) & 23.5 & 26.1 & 5.4 \\
\hline Ongoing biological DMARDs (\%) & 73.9 & 73.1 & 86.5 \\
\hline \multicolumn{4}{|l|}{ Previously diagnosed (\%) } \\
\hline Cardiovascular disease & 7.0 & 7.6 & 2.7 \\
\hline Hypertension & 26.0 & 27.4 & 18.9 \\
\hline Diabetes & 7.5 & 8.3 & 5.4 \\
\hline COPD & 4.5 & 5.8 & 0 \\
\hline OSAS & 2.0 & 1.9 & 2.8 \\
\hline Other CRD & 1.0 & 1.3 & 0 \\
\hline Smoking (\%): current/past & $30.2 / 24.6$ & $25.6 / 25.0$ & $48.6 / 21.6$ \\
\hline Lipid lowering therapy (\%) & 14.6 & 16.7 & 5.4 \\
\hline Anti-platelet therapy (\%) & 9.0 & 9.6 & 2.7 \\
\hline Anti-osteoporotic drug (\%) & 17.6 & 19.1 & 2.9 \\
\hline
\end{tabular}

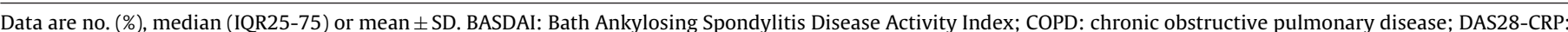

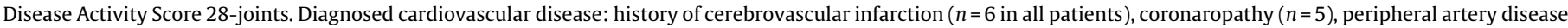

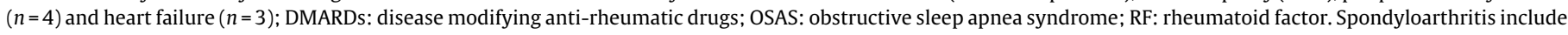
13 psoriatic arthritis and 24 axial spondyloarthritis. 
Table 2

Standardized multimorbidity assessment in inflammatory arthritis.

\begin{tabular}{|c|c|c|c|}
\hline & $\begin{array}{l}\text { All patients } \\
(n=200)\end{array}$ & $\mathrm{RA}(n=157)$ & Spondyloarthritis $(n=37)$ \\
\hline Android obesity & $90(49.7)$ & $65(46.4)$ & $22(61.1)$ \\
\hline \multicolumn{4}{|l|}{ Diabetes } \\
\hline Undiagnosed & $7(4.0)$ & $4(2.96)$ & $1(2.86)$ \\
\hline Uncontrolled & $4(2.0)$ & $3(1.91)$ & $1(2.70)$ \\
\hline Dyslipidemia $(\geq 1.6 \mathrm{~g} / \mathrm{L})$ & $29(16.1)$ & $19(13.2)$ & $9(29.0)$ \\
\hline \multicolumn{4}{|l|}{ Hypertension } \\
\hline Undiagnosed & $25(12.6)$ & $19(12.2)$ & $5(13.5)$ \\
\hline Uncontrolled & $16(8.0)$ & $15(9.6)$ & $0(0.0)$ \\
\hline Undiagnosed peripheral arterial disease & $9(4.5)$ & $7(4.5)$ & $1(2.7)$ \\
\hline Carotid plaques & $111(59.7)$ & $105(70.9)$ & $14(42.4)$ \\
\hline Carotid stenosis & $12(6.5)$ & $12(8.1)$ & $0(0.0)$ \\
\hline Aortic aneurysm & $10(5.5)$ & $7(4.8)$ & $2(6.2)$ \\
\hline Left ventricular hypertrophy & $6(3.8)$ & $5(4.3)$ & $0(0.0)$ \\
\hline Valvulopathies & $32(16.8)$ & $25(16.9)$ & $5(13.5)$ \\
\hline Cardiac hypokinesia & $3(1.6)$ & $2(1.3)$ & $1(2.7)$ \\
\hline mSCORE & $n=190^{b}$ & $n=147^{b}$ & $n=37^{b}$ \\
\hline Low risk & $48(25.3)$ & $14(9.5)$ & $30(81.1)$ \\
\hline Intermediate risk & $81(42.6)$ & $72(49.0)$ & $7(18.9)$ \\
\hline High risk & $31(16.3)$ & $31(21.1)$ & 0 \\
\hline Very high risk & $30(15.8)$ & $30(20.4)$ & 0 \\
\hline mUS-SCORE & & $n=156^{\mathrm{b}}$ & \\
\hline Low risk & NA & $13(8.3)$ & NA \\
\hline Intermediate risk & NA & $23(14.7)$ & NA \\
\hline High risk & NA & $8(5.1)$ & NA \\
\hline Very high risk & NA & $112(71.8)$ & NA \\
\hline Undiagnosed pulmonary obstruction ${ }^{\mathrm{a}}$ & $18(15.5)$ & $16(18.8)$ & $2(7.14)$ \\
\hline Undiagnosed risk of sleep apnea & $75(40.1)$ & $54(36.5)$ & $17(50.0)$ \\
\hline Cancer screening to complete & $79(39.9)$ & $64(41.3)$ & $13(35.1)$ \\
\hline Dental care to complete & $14(7.0)$ & $12(7.64)$ & $2(5.41)$ \\
\hline Vaccine calendar to complete & $105(52.8)$ & $82(52.6)$ & $20(54.0)$ \\
\hline Vitamin D insufficiency & $69(34.5)$ & $57(36.3)$ & $10(27.0)$ \\
\hline FRAX (median, IQR25-75) & $6(4-11)$ & $6.5(4.2-12.0)$ & $4.10(2.50-5.90)$ \\
\hline Anti-osteoporotic drug need & $22(11.0)$ & $22(14.0)$ & $0(0.0)$ \\
\hline Anxiety & $47(25.5)$ & $37(25.2)$ & $9(28.1)$ \\
\hline Depression & $10(5.5)$ & $8(5.5)$ & $2(6.2)$ \\
\hline Precariousness & $74(40.2)$ & $59(40.7)$ & $15(42.9)$ \\
\hline Moritsky score (median, IQR25-75) & $4(3-4)$ & $4(3-4)$ & $4(3-4)$ \\
\hline
\end{tabular}

Data are no. (\%) unless indicated.

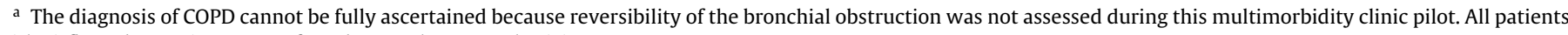
with airflow obstruction were referred to a pulmonary physician.

b Number of patients with data available. Of note, if lipid measures were missing, mSCORE could not be calculated but in presence of carotid plaque, those patients could be

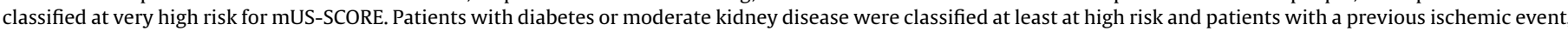

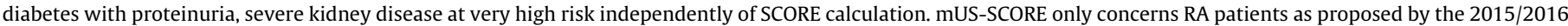
update of EULAR CVR recommendations.

54.6\%-67.9\%) showed undiagnosed or uncontrolled hypertension, dyslipidaemia, diabetes, abdominal aorta aneurysm, carotid stenosis, cardiopathy, osteoporosis or lung disease.

In total, $6 \%$ (3.4-10.4\%) of patients had undiagnosed or uncontrolled diabetes and 20.6\% (15.5-27.7\%) had undiagnosed or uncontrolled hypertension. Overall, 4.5\% (2.4-8.3\%) of patients showed undiagnosed lower-limb peripheral arterial disease, 6.5\% (3.7-11.0\%) carotid stenosis and 5.5\% (3.0-9.8\%) aortic aneurysm. Echocardiography showed left ventricular hypertrophy in $3.8 \%(1.7-8.0 \%)$ of patients, significant valvulopathies in $16.8 \%(12.2-22.8 \%)$ and hypokinesia in $1.6 \%$ (0.5-4.5\%).

We found undiagnosed pulmonary obstruction and risk of OSAS in $15.5 \%(10.0-23.2 \%)$ and $40.1 \%(33.3-47.3 \%)$ of patients, Moreover, $39.9 \%$ (33.3-46.8\%) were not up to date on cancer screening and $52.8 \%(45.8-59.6 \%)$ on the vaccine schedule. An anti-osteoporotic drug was required for $11 \%(7.4-16.1 \%)$ of the patients. Anxiety was found in $25.5 \%$ (19.8-32.3\%) of patients, depression in $5.5 \%$ (3.0-9.8\%) and precarity in $40.2 \%$ (33.4-47.4\%).

The comparison of cardiovascular risk estimate using ultrasonography (according to EULAR recommendations update [7]) or not has been discussed elsewhere [11].

\subsection{Evaluation of recommendation applications according to patient's declarations}

Two hundred patients were called by phone 3 to 12 months after baseline and were asked if they had followed the recommendations given at screening. The percentage of patients with recommendation given at screening and who declared to have applied it is presented in Fig. 1A. Vaccinations were performed in $51.8 \%$ of patients needing pneumococcus vaccine, $43.9 \%$ diphtheria-tetanus-poliomyelitis and 31.4\% influenzae. Moreover, $23.3 \%$ updated cancer screening. Concerning referral, $50 \%$ consulted endocrinologist as proposed, $43.6 \%$ a physiotherapist, $37.5 \%$ a lung disease specialist and $52.1 \%$ a cardiologist. Blood pressure was controlled \pm in $72.3 \%$ of patients and lipids in $58.6 \%$. The reasons for not following recommendations were unawareness (36.4\%), "in progress” (35.9\%), refusal (15.7\%) and forgetting (9.9\%) (Fig. 1B).

\section{Discussion}

Our multimorbidity clinic investigated all the points to consider proposed by EULAR to report multimorbidities, risk factors and prevention. On the top of that, our clinic also explored lung 


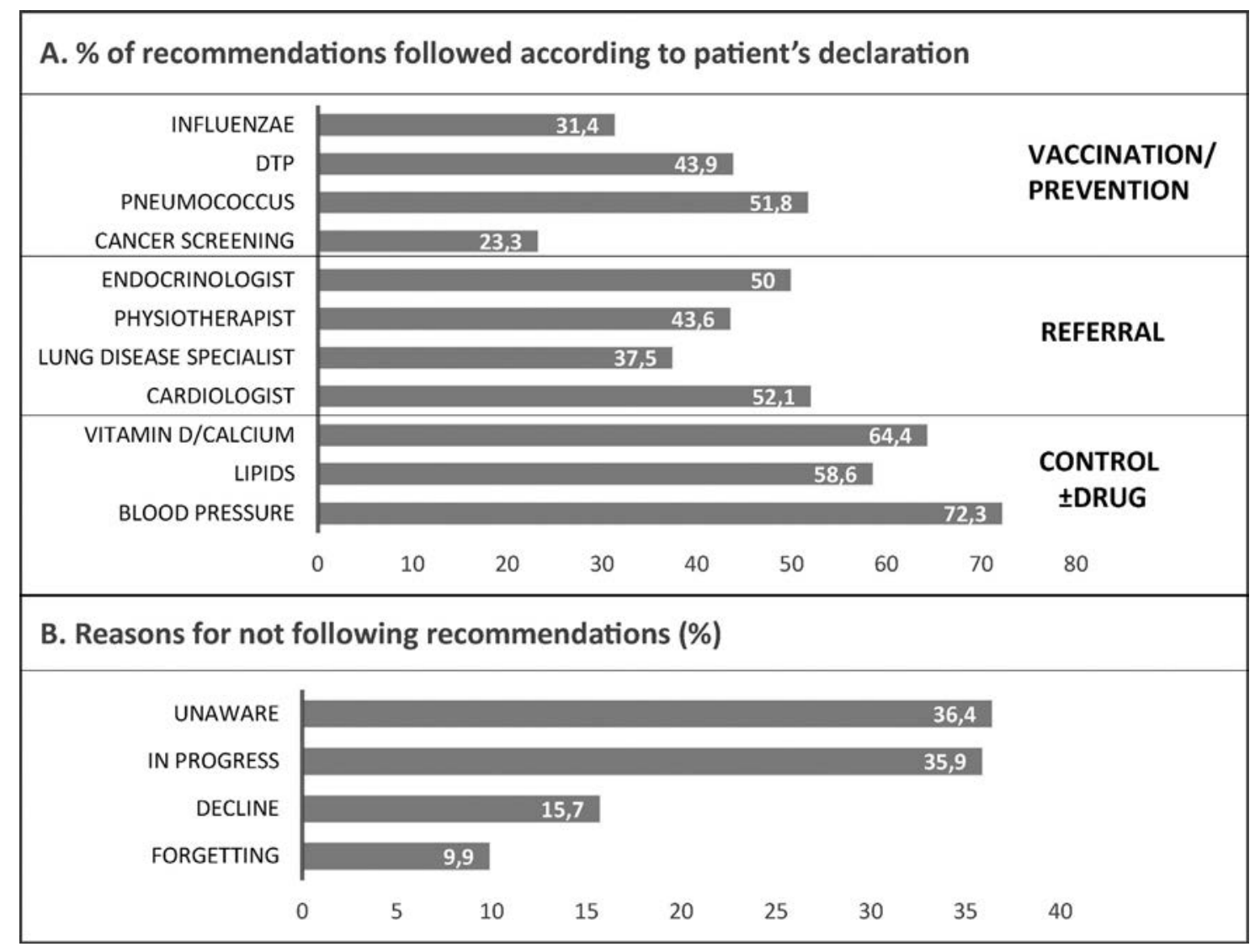

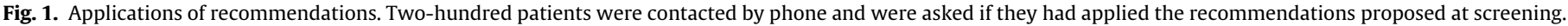
A. Percentage of patients who declared to have applied recommendations. B. Reasons for not following recommendation. DTP: diphtheria-tetanus-poliomyelitis.

diseases, alcohol dependence and anxiety. We also performed physical examination, biologic exams and imaging to screen those multimorbidities during the 1-day clinic. These included first level spirometry and questionnaires for lung diseases, 4-limb blood pressure, supra-aortic trunks and abdominal aorta ultrasonography for hypertension and peripheral arterial disease as well as echocardiography for cardiopathy.

The most common multimorbidities already diagnosed in our patients were hypertension (26\%) and diabetes (7.5\%). The systematic screening diagnosed at least one undiagnosed or uncontrolled diseases in $61 \%$ patients. The most frequent were hypertension (20.6\%), dyslipidemia (16.1\%) valvulopathies (16.8\%) and diabetes (6\%). The findings for CVD risk factor assessment and osteoporosis were similar to the COMEDRA study that included patients with RA and 6\% patients required diabetes management and 30\% blood pressure management [12].

More than half of the patients lacked at least one vaccination. Previous studies showed that the main reason for non-vaccination is the lack of proposal [13]. Absence of vaccination and cancer screening might be explained by the fact that patients with chronic inflammatory rheumatic disease are mainly followed by their rheumatologist and rarely consult their general practitioner. Educational programs for patients and physicians are needed to improve vaccination and cancer screening.

This study also underlines the relevance of lung disease screening in chronic inflammatory rheumatic diseases. Indeed, it resulted in our population in $55.6 \%$ of referrals to a pulmonary specialist. Prior studies showed that OSAS is common in patients with RA and ankylosing spondylitis (about 20\%) [3,14] and that the Epworth Sleepiness Scale (ESS) is reliable in this population [15]. We are currently collecting data to assess the number of OSAS confirmed by polysomnography. The EULAR recommendations do not propose specific lung disease screening. As sleep apnea is an important cardiovascular risk factor and is promoted by obesity which is increased in RA patients, its detection should be added to systematic screening. Undiagnosed possible COPD was also detected in $15.5 \%$ of patients, who were targeted for further exploration and consultation to a respiratory specialist.

If the relevance of systematic screening of multimorbidities is established for CVD detection, the main problem remains the organization of such a screening, which is time-consuming. A 1-day clinic seems adapted as indicated by the limited number of missing data. The small number of patients (12/212) who did not visit for the hospitalization shows that screening was well accepted by patients. Initiative, such as the French one published by Gossec L et al., summarizing the most recent recommendations applying in each country to manage multimorbidities would be helpful for rheumatologists [16].

The cost-effectiveness of screening strategies is not clear for every disease. According to national and EULAR recommendations, some screenings such as prostate cancer were limited to very specific at-risk population as concerns about the effectiveness of a systematic screening have been raised, because of the risk of overtreatment. As discussed in the EULAR recommendations [5], Canadian data suggested that routine screening for depression in increased rates of treatment without reducing the burden of depression [17]. In the present study, patients identified as at risk of depression were referred to specialist but the impact of the referral was not assessed. Adherence was assessed in the present study. Patients with low adherence were given explanations about the potential impacts of not taking their treatment and were referred to educational programs. However, the impact of those program on 
adherence has not been clearly demonstrated [18]. Studies exploring different approaches to improve adherence are still needed.

To assess the adhesion on recommendations given, 200 patients were called 3-12 months after screening. The data are only declarative but results are encouraging. About half patients performed vaccination (less for influenzae but this vaccine is seasonal) or consulted a specialist as requested (37.5-52.1\%, with the lowest referral rate for lung disease specialist). Only $23.3 \%$ up-dated cancer screening. The next step would be to evaluate the impact of such screening on morbimortality and drug consumption. Such data are lacking in general population and in rheumatic disease [19].

Based on expert opinion, EULAR recommends a standardized periodical review at least every 5 years [7] and CVD risk screening at least every 5 years, with stratification according to risk level: every 5 years for low risk patients and sooner for intermediate and high risks [7]. In our clinic, we proposed to perform this complete screening every 5 years. Recently, we added an annual consultation dedicated on multimorbidity assessment. To check whether the recommendations given at the initial screening have been applied or not and reiterate advice if needed, we will evaluate in the future the impact of such strategy. Once again, more studies are needed to assess the most cost-effective screening periodicity. Strengths and limitations: The study was performed in a single reference center in the standardized multimorbidity clinic of the hospital. The study was performed in daily practice, which reflects real life but implies a few missing data. The patients included in this work are not representative of a general population of patients with inflammatory rheumatisms. First, patients with the most severe multimorbidities may have been excluded because those with a current cardiologist follow-up or those who had already been screened for multimorbidities were not included. The exact number of patients who were not proposed the screening because of cardiologist follow-up has not been collected. Then, most patients were treated with biological drugs and 4 times more RA than SpA patients were screened. This reflects the choice of rheumatologists to propose, in real life, this screening to patients at the highest CVD risk. On the other hand, rheumatologists usually manage multimorbidities when the rheumatism itself is controlled. This is the case in this study, as most patients had a with low disease activity. EULAR guidelines recommend assessing lipid profile in patients with low levels of inflammation [7]. Indeed, inflammation is associated with decreased cholesterol levels. Including patients with more disease activity may have given different results with lower mSCORE and eventually underestimation of the CVD risk and dyslipidemia. Another limitation is due to the cross-sectional design of the study. Indeed, we classified patients as having hypertension or diabetes based on a single-day assessment. However, for blood pressure, it was assessed 3 times after 10 minutes of rest.

In conclusion, systematic screening of multimorbidities based on EULAR recommendations is efficient and feasible. One-day clinic is well appropriate. Screening for lung diseases is also worthwhile and should be added to this systematic screening. Systematic screening of multimorbidities should be proposed to every patient with chronic inflammatory rheumatic diseases.

\section{Disclosure of interest}

The authors declare that they have no competing interest.

\section{Acknowledgments}

We thank Ariane Sultan, Rodolphe Bourret, Jean Ribstein, Antoine Avignon and Jean-Paul Cristol for development of the comorbidity clinic and Thibault Mura for data management and statistic analysis.

\section{Appendix A. Supplementary data}

Supplementary data associated with this article can be found, in the online version, at https://doi.org/10.1016/j.jbspin.2018.03.016.

\section{References}

[1] World Health Organization. 2008-2013 Action plan for the global strategy for the prevention and control of non communicable diseases. Prevent and control cardiovascular diseases, cancers, chronic respiratory diseases Diabetes; 2008 http://www.google.fr/url? sa=t\&rct=j\&q=\&esrc=s\&source=web\&cd=1\&ved= 0ahUKEwjZ5bLaucHaAhUPa8AKHRxICAIQFggoMAA\&url=http\%3A\%2F\% 2Fwww.who.int\%2Fnmh\%2Fpublications\%2Fncd_action_plan_en.pdf\&usg= AOvVaw1pBD89j3jVJSYS8RD5rUm7.

[2] Bousquet J, Jorgensen C, Dauzat M, et al. Systems medicine approaches for the definition of complex phenotypes in chronic diseases and ageing. From concept to implementation and policies. Curr Pharm Des 2014;20:5928-44.

[3] Solak O, Fidan F, Dündar U, et al. The prevalence of obstructive sleep apnoea syndrome in ankylosing spondylitis patients. Rheumatol 2009;48:433-5.

[4] Ungprasert P, Srivali N, Cheungpasitporn W, et al. Risk of incident chronic obstructive pulmonary disease in patients with rheumatoid arthritis: A systematic review and meta-analysis. Joint Bone Spine 2016;83:290-4.

[5] Baillet A, Gossec L, Carmona L, et al. Points to consider for reporting, screening for and preventing selected comorbidities in chronic inflammatory rheumatic diseases in daily practice: a EULAR initiative. Ann Rheum Dis 2016;75: 965-73.

[6] European Stroke Organisation, Tendera M, Aboyans V, et al. ESC Guidelines on the diagnosis and treatment of peripheral artery diseases: document covering atherosclerotic disease of extracranial carotid and vertebral, mesenteric, renal, upper and lower extremity arteries: the Task Force on the diagnosis and treatment of peripheral artery diseases of the European Society of Cardiology (ESC). Eur Heart J 2011;32:2851-906.

[7] Agca R, Heslinga SC, Rollefstad S, et al. EULAR recommendations for cardiovascular disease risk management in patients with rheumatoid arthritis and other forms of inflammatory joint disorders: 2015/2016 update. Ann Rheum Dis 2017;76:17-28.

[8] Pauwels RA, Buist AS, Ma P, et al., GOLD Scientific Committee. Global strategy for the diagnosis, management, and prevention of chronic obstructive pulmonary disease: National Heart, Lung, and Blood Institute and World Health Organization global initiative for chronic obstructive lung disease (GOLD): executive summary. Respir Care 2001;46:798-825.

[9] Briot K, Cortet B, Roux C, et al. 2014 update of recommendations on the prevention and treatment of glucocorticoid-induced osteoporosis. Joint Bone Spine 2014;81:493-501.

[10] Touboul P-J, Hennerici MG, Meairs S, et al. Mannheim carotid intima-media thickness consensus (2004-2006). An update on behalf of the Advisory Board of the 3rd and 4th Watching the Risk Symposium, 13th and 15th European stroke conferences, Mannheim, Germany, 2004, and Brussels, Belgium, 2006. Cerebrovasc Dis 2007;23:75-80.

[11] Daïen CI, Tubery A, Cailar GD, et al. Application of the 2015/2016 EULAR recommendations for cardiovascular risk in daily practice: data from an observational study. Ann Rheum Dis 2018;77:625-6.

[12] Dougados M, Soubrier M, Perrodeau E, et al. Impact of a nurse-led programme on comorbidity management and impact of a patient self-assessment of disease activity on the management of rheumatoid arthritis: results of a prospective, multicentre, randomised, controlled trial (COMEDRA). Ann Rheum Dis 2015;74:1725-33.

[13] Hua C, Morel J, Ardouin E, et al. Reasons for non-vaccination in French rheumatoid arthritis and spondyloarthritis patients. Rheumatol 2015;54:748-50.

[14] Mutoh T, Okuda Y, Mokuda S, et al. Study on the frequency and risk factors of moderate-to-severe sleep apnea syndrome in rheumatoid arthritis. Mod Rheumatol 2016;26:681-4.

[15] Gjevre JA, Taylor-Gjevre RM, Nair BV, et al. Do sleepy rheumatoid arthritis patients have a sleep disorder? Musculoskeletal Care 2012;10:187-95.

[16] Gossec L, Baillet A, Dadoun S, et al. Collection and management of selected comorbidities and their risk factors in chronic inflammatory rheumatic diseases in daily practice in France. Joint Bone Spine 2016;83:501-9.

[17] Joffres M, Jaramillo A, Dickinson J, et al. Canadian task force on preventive health C. Recommendations on screening for depression in adults. CMAJ 2013;185:775-82.

[18] Marengo MF, Suarez-Almazor ME. Improving treatment adherence in patients with rheumatoid arthritis: what are the options? Int J Clin Rheumtol 2015;10:345-56.

[19] Smith SM, Wallace E, O'Dowd T, et al. Interventions for improving outcomes in patients with multimorbidity in primary care and community settings. Cochrane Database Syst Rev 2016;14:CD006560. 